\title{
Coexpression of epidermal growth factor receptor with related factors is associated with a poor prognosis in non-small-cell lung
}

\section{cancer}

\author{
DEB Swinson*,', G Cox² and KJ O'Byrne ${ }^{3}$ \\ 'Cancer Centre, Queen Elizabeth Hospital, Edgbaston, Birmingham BI 5 2TH, UK; ${ }^{2}$ Kingsmill Hospital, Mansfield, Nottingham NGI IAA, UK; ${ }^{3}$ Thoracic \\ Oncology Research Group, St James's Hospital, Dublin 8, Ireland, UK
}

\begin{abstract}
The epidermal growth factor receptor (EGFR) is commonly expressed in non-small-cell lung cancer (NSCLC) and promotes a host of mechanisms involved in tumorigenesis. However, EGFR expression does not reliably predict prognosis or response to EGFR-targeted therapies. The data from two previous studies of a series of I 8 I consecutive surgically resected stage I-IIIA NSCLC patients who had survived in excess of 60 days were explored. Of these patients, tissue was available for evaluation of EGFR in 179 patients, carbonic anhydrase (CA) IX in 177 patients and matrix metalloproteinase-9 (MMP-9) in 169 patients. We have previously reported an association between EGFR expression and MMP-9 expression. We have also reported that MMP-9 $(P=0.00 \mathrm{I})$ and perinuclear (p)CA IX $(P=0.03)$ but not EGFR expression were associated with a poor prognosis. Perinuclear CA IX expression was also associated with EGFR expression $(P<0.00 \mathrm{I})$. Multivariate analysis demonstrated that coexpression of MMP-9 with EGFR conferred a worse prognosis than the expression of MMP-9 alone $(P<0.00 I)$ and coexpression of EGFR and pCA IX conferred a worse prognosis than $P C A I X$ alone $(P=0.05)$. A model was then developed where the study population was divided into three groups: group I had expression of EGFR without coexpression of MMP-9 or PCA IX (number = 21); group 2 had no expression of EGFR (number =75); and group 3 had coexpression of EGFR with pCA IX or MMP-9 or both (number=70). Group 3 had a worse prognosis than either groups 1 or $2(P=0.0003$ and 0.027 , respectively) and group 1 had a better prognosis than group 2 $(P=0.036)$. These data identify two cohorts of EGFR-positive patients with diametrically opposite prognoses. The group expressing either EGFR and or both MMP-9 and pCA IX may identify a group of patients with activated EGFR, which is of clinical relevance with the advent of EGFR-targeted therapies.
\end{abstract}

British Journal of Cancer (2004) 91, I30 I- | 307. doi: I0.1038/sj.bjc.6602 I 49 www.bjcancer.com

Published online 7 September 2004

(c) 2004 Cancer Research UK

Keywords: CA IX; NSCLC; EGFR; MMP-9

Epidermal growth factor receptor (EGFR) is a member of the cerbB membrane receptor family and was first described in 1980 (Cohen et al, 1980). Epidermal growth factor receptor signalling promotes angiogenesis, cell proliferation, tumour invasion and inhibits tumour suppressor gene activity and apoptotic signalling (Westermark et al, 1982; Abdollahi et al, 1999; Rosen et al, 2001; Gildea et al, 2002; Hirata et al, 2002; Di Gennaro et al, 2003). Recently, the clinical relevance of the EGFR has been heightened in light of the development of the EGFR tyrosine kinase inhibitors, Getifinib and Erlotinib and EGFR monoclonal antibodies Cetuximab that have been demonstrated to have antitumour activity in solid tumours including non-small cell lung cancer (NSCLC) (Giaccone et al, 2004; Herbst et al, 2004a, b; Lynch et al, 2004b).

Immunohistochemical studies have reported EGFR overexpression in $22-81 \%$ of NSCLC tumours depending on the antibody used and cut point that defines overexpression (Veale et al, 1987; Volm et al, 1993; Pfeiffer et al, 1996; Cornianu and Tudose, 1997; Pastorino et al, 1997; Rusch et al, 1997; Fontanini et al, 1998;

*Correspondence: Dr DEB Swinson; E-mail: daniel.swinson@fsmail.net Received 17 March 2004; revised I4 July 2004; accepted 16 July 2004; published online 7 September 2004
Greatens et al, 1998; D'Amico et al, 1999; Fu et al, 1999; Cox et al, 2000; Ohsaki et al, 2000; Selvaggi et al, 2002; Hirsch et al, 2003; Kanematsu et al, 2003; Mukohara et al, 2003; Onn et al, 2003). The majority of these studies have failed to demonstrate an association with prognosis (Table 1). This may be because EGFR activation usually requires the binding of specific ligands prior to induction of phosphorylation of the tyrosine domain of the receptor and subsequent dimerisation with either another EGFR molecule or with another member of the c-erbB family of receptors (Cohen et al, 1981; Yarden and Ullrich, 1988; Tzahar et al, 1996). Hence, expression of EGFR alone may not accurately represent EGFR activity. However, coexpression of EGFR with neither its most common dimerisation partner, C-erbB2, nor its most common ligand, transforming growth factor (TGF) $\alpha$, predict prognosis (Rusch et al, 1997; Kanematsu et al, 2003). Despite these observations, studies that are able to identify patients with activated EGFR may identify patients with a poor outcome. This contention is supported by a small study of 36 patients with resected NSCLC tumours, which reported that phosphorylated EGFR expression is associated with a poor prognosis (Kanematsu et al, 2003). Therefore, coexpression of EGFR with downstream factors may identify such patients and add credence to this hypothesis. 
Table I Immunohistochemical studies of EGFR expression in NSCLC

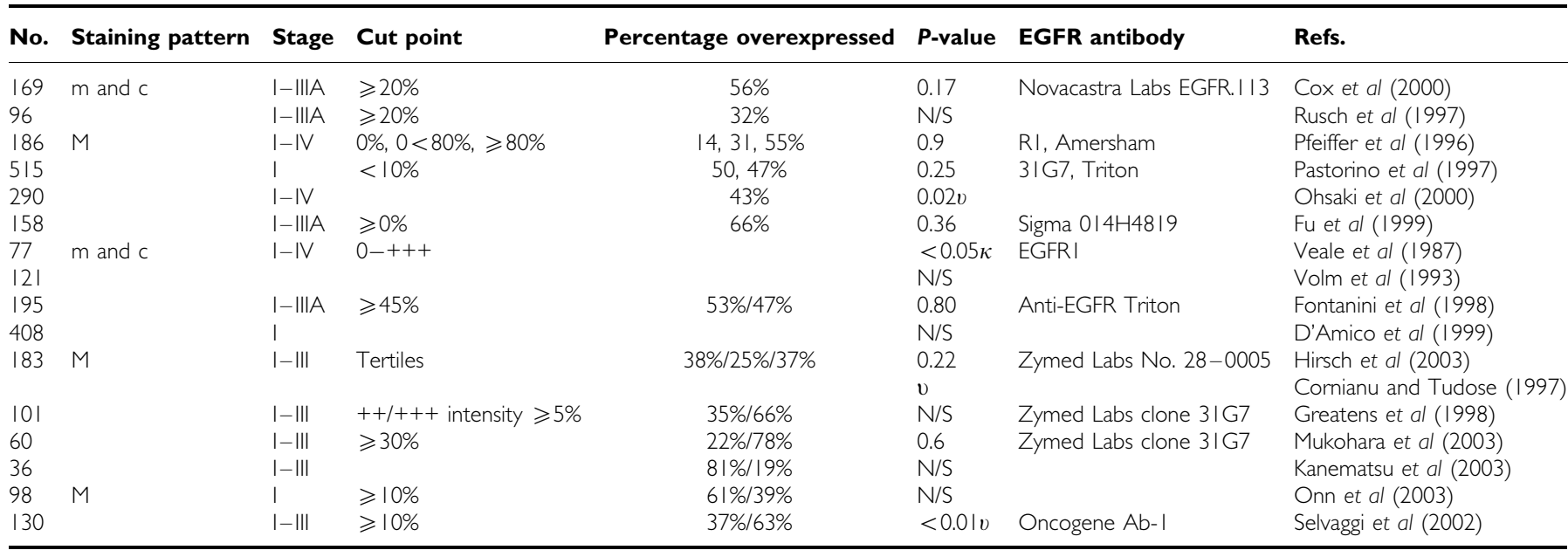

$\mathrm{EGFR}=$ epidermal growth factor receptor; $\mathrm{S}=$ significant; $\mathrm{N} / \mathrm{S}=$ not significant; $v$ associated with a poor prognosis; $\kappa$ associated with stage survival analysis not performed.

In our series of patients with NSCLC, the expression of EGFR was not associated with prognosis (Cox et al, 2000). However, an important relationship was found between EGFR and matrix metalloproteinase (MMP)-9 expression. Matrix metalloproteinase-9 is an enzyme involved in the degradation of the extracellular matrix and increased expression was associated with a poor prognosis. Coexpression of EGFR and MMP-9 identified a subset of patients with a significantly worse prognosis than either EGFR or MMP-9 alone (Cox et al, 2000). In vitro experiments demonstrate that EGF stimulation of EGFR-positive NSCLC cell lines can result in the upregulation of MMP-9 and, likewise, inhibition of EGFR in vivo reduces tumour cell MMP-9 expression (Perrotte et al, 1999; O'Byrne et al, 2001). These data suggest that coexpression of MMP-9 and EGFR may identify patients with activated EGFR.

Carbonic anhydrase (CA) IX is a marker of hypoxia and is regulated by the transcription factor hypoxia-inducible factor (HIF)-1 $\alpha$ (Wykoff et al, 2000; Swinson et al, 2003). Expression of CA IX is associated with a poor prognosis in NSCLC (Giatromanolaki et al, 2001; Swinson et al, 2003). EGF treatment of tumour cell lines induces HIF- $1 \alpha$ expression and constitutively active mutations of EGFR potentiate hypoxic induction of other targets of HIF- $1 \alpha$ such as VEGF (Clarke et al, 2001; Semenza, 2002). Giatromanolaki et al reported an association between CA IX and EGFR and we have reported an association between EGFR and HIF-1 $\alpha$ (Giatromanolaki et al, 2001; Swinson et al, 2004). These data suggest that coexpression of CA IX and EGFR may also identify patients with activated EGFR.

The aims of this study were to first update the survival data from previous studies of EGFR, MMP-9 and CA IX in a series of surgically resected NSCLC, assess if an association exists between EGFR and CA IX and develop a model using EGFR and related downstream factor expression to predict the outcome in NSCLC.

\section{MATERIALS AND METHODS}

\section{Ethics}

The Leicester locoregional ethical committee granted ethical approval for these studies.

\section{Patient inclusion and exclusion criteria and follow-up}

A consecutive series of patients who had had NSCLC tumours resected with curative intent were considered for entry into the two studies. Patients were excluded if tissue from the resected specimen was not available, if they had pathologically staged stage
IV disease or survival of less than 61 days from time of operation so as to exclude the confounding factor of perioperative mortality (Cox et al, 2000; Swinson et al, 2003). The final staging was based on the findings at surgery and the histopathology report. Hospital notes of the patients were reviewed, and if necessary, the local cancer registries or patient's general practitioner were contacted to complete case follow-up.

\section{Immunohistochemistry}

The specimens had previously been evaluated for the expression of EGFR, MMP-9 and CA IX. Standard immunohistochemical methods were employed using the anti-EGFR mouse monoclonal antibody (Mab) EGFR.113 (Novocastra Laboratories Ltd, Newcastle, UK) (Cox et al, 2000), anti-MMP-9 mouse Mab 56-2A4 (Chemicon International Ltd, Temecula, CA 92590, USA) (Cox et al, 2000) and anti-CA IX antibody M75 (Gift from Professor J Pastorek, Institute of Virology, Slovak Academy of Sciences, Slovak Republic) (Table 2) (Swinson et al, 2003).

\section{Interpretation}

The percentage of cells staining positively in each study was estimated using light microscopy. The cut points used to dichotomise the series in each study were predetermined. In all, $20 \%$ plus tumour cell staining was used as a cut point to define overexpression of EGFR (both cytoplasmic and membranous) and MMP-9 (cytoplasmic) (Cox et al, 2000). Two independent investigators, blinded from the other's results interpreted the slides and where a discrepancy was found a consensus was reached using a double-headed microscope. In the second study, there were three distinct patterns of CA IX staining perinuclear (p), membranous $(\mathrm{m})$ and cytoplasmic. The presence or absence of pCA IX staining was used as a cut point, as this pattern of staining was an infrequent observation. Greater or equal to the median defined high mCA IX staining (Swinson et al, 2003). Two investigators blinded from each other's results again interpreted the staining. A third investigator adjudicated the result where discrepancies were found. The survival data from these studies were reviewed and updated.

\section{Literature search for studies investigating EGFR expression in NSCLC}

Pubmed, Embase, Medline databases, the Cochrane library and ASCO annual meeting abstracts were searched using EGFR, NSCLC and immunohistochemistry as key words. 
Table 2 Immunohistochemistry techniques and antibodies

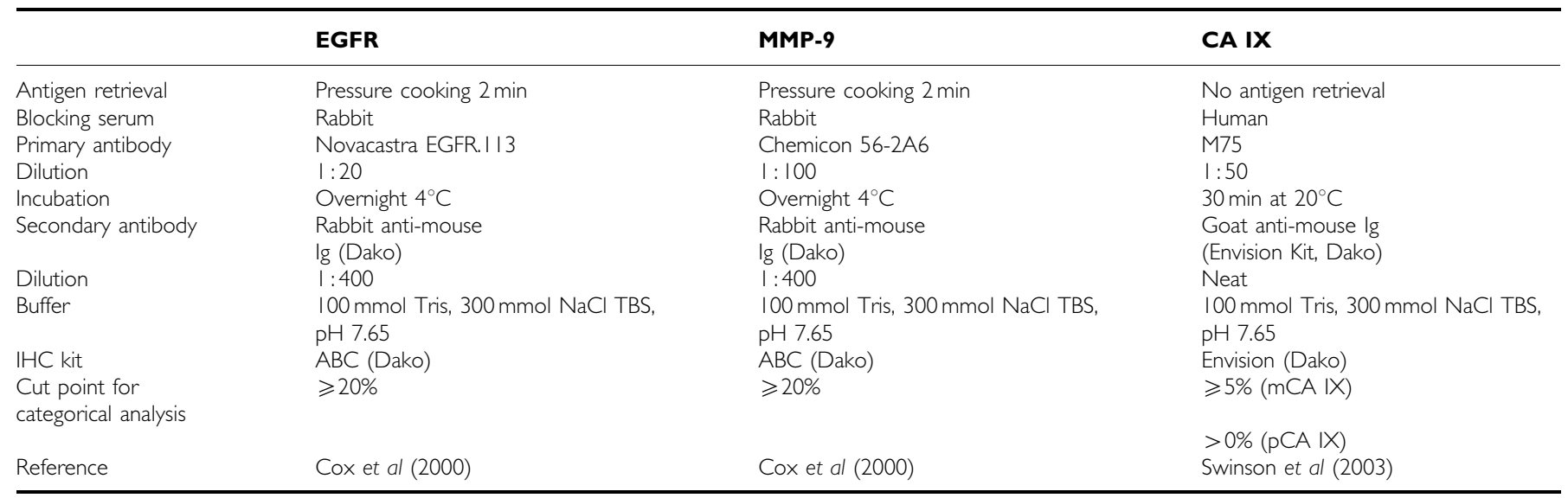

$\mathrm{EGFR}=$ epidermal growth factor receptor; $\mathrm{MMP-9}=$ metalloproteinase-9; $\mathrm{pCA}=$ perinuclear carbonic anhydrase; $\mathrm{mCA}=$ membranous carbonic anhydrase.

\section{Statistical analysis}

The SPSS software system (SPSS for Windows Version 9.0) was used to perform the statistical analysis. The $\chi^{2}$-test was used to analyse the associations between categorical variables. A $P$-value of $\leqslant 0.05$ was used as the level of significance. Overall survival as opposed to cancer specific mortality was used to avoid bias. Survival curves were plotted using the Kaplan-Meier method and a log-rank test was used to assess the statistical significance of differences in survival. A Cox proportional-hazards regression model was used to investigate whether coexpression of factors with EGFR significantly worsened outcome compared to expression of factors in isolation. A Cox proportional-hazards regression model was also used to identify statistically significant differences in survival and estimate hazard ratios and 95\% confidence intervals (CI). Covariables were entered into the model if $P \leqslant 0.05$ and removed if $P \geqslant 0.1$.

\section{RESULTS}

\section{Study population}

In all, 218 patients were considered for the two studies. Of these, 24 patients were excluded due to poor postoperative survival and 13 patients were excluded as they were found to have pathological stage IV disease. Of the 181 patients, tissue was available from 179 patients for staining for EGFR expression, from 177 patients for staining for CA IX expression and from 169 patients for staining for MMP-9 expression. In total, there were 166 cases stained for all three markers. Of the 166 patients available for analysis, 115 $(69.3 \%)$ were male and $51(30.7 \%)$ were female. A total of 82 (49.4\%) patients had stage I, $46(27.7 \%)$ patients had stage II and 38 patients had stage IIIA $(22.9 \%)$ disease. A total of $47(28.2 \%)$ patients had adenocarcinoma, $101(60.8 \% \%)$ patients had squamous carcinoma, $14(8.4 \%)$ patients had large-cell carcinoma and four $(2.4 \%)$ patients had tumours that were not characterised. The mean age at surgery was 65 years (s.d. 7.9, range 33.8-79.1). Positive resection margins were found in 15 patients. One patient had received adjuvant chemotherapy. Adjuvant radiotherapy was given to 17 patients, of whom 10 were stage IIIA, six were stage II and one was stage I.

In total, $126(75.9 \%)$ patients had died at the time of analysis and of these $18(10.8 \%)$ were not cancer related. The duration of follow-up from the time of surgery was between 5 and 10 years.

Of the 15 patients who had been excluded due to lack of tissue, there was no statistical difference in the stage $(P=0.72)$, histology $(P=0.9)$, sex $(P=0.56)$ or adjuvant radiotherapy
$(P=0.56)$ distribution compared to the patients used in the survival analysis.

\section{Associations between different patterns of CA IX staining and EGFR}

Using the $\chi^{2}$ test membranous carbonic anhydrase (mCA) IX and pCA IX expression patterns were positively associated with EGFR expression. The association between pCA IX and EGFR expression was the strongest $(P<0.001)$. All the pCA IX-positive tumours expressed mCA IX. The association between the mCA IX group and EGFR was dependent on the pCA IX-positive cases, as it was lost when the pCA IX group was subtracted from the series $(P=0.93)$ (Table 3). Perinuclear CA IX was therefore used in survival analyses for this review.

There was a trend for a positive association between pCA IX and MMP-9 expression $(P=0.09)$ (Table 3$)$.

\section{Survival analysis for EGFR-related variables}

Survival data for EGFR, pCA IX and MMP-9 expression were updated for the study and there was no significant change in the

Table 3 Frequency table for PCA IX, EGFR and MMP-9 expression

\begin{tabular}{lccc}
\hline Factor & Negative pCA IX & Positive pCA IX & $\chi^{2}$ P-value \\
\hline EGFR $(N=176)$ & 73 & 11 & \\
$<20 \%$ & 58 & 34 & $<0.001$ \\
$\geqslant 20 \%$ & & & \\
MMP-9 $(N=166)$ & 61 & 18 & \\
Low & 59 & 28 & \\
High & & &
\end{tabular}

\begin{tabular}{cccc} 
& Low mCA IX & High mCA IX \\
\hline$E G F R(N=176)$ & & & \\
$<20 \%$ & 53 & 31 & 0.009 \\
$\geqslant 20 \%$ & 40 & 52 &
\end{tabular}

\begin{tabular}{|c|c|c|c|}
\hline & Low mCA IX & High mCA IX & \\
\hline \multicolumn{4}{|c|}{ pCA IX-positive cases subtracted EGFR $(N=130)$} \\
\hline$<20 \%$ & 50 & 22 & 0.79 \\
\hline$\geqslant 20 \%$ & 39 & 19 & \\
\hline
\end{tabular}


previously reported outcomes (data not shown) (Cox et al, 2000; Swinson et al, 2003). Using the log-rank test, MMP-9 $(P=0.0015)$ and pCA IX $(P=0.03)$ were associated with a poor prognosis and EGFR expression had no prognostic value $(P=0.72)$ (Figures $1-$ $3)$.

Using Cox's regression analysis to estimate hazard ratios, coexpression of EGFR with pCA IX, mCA IX or MMP-9 increased the hazard ratio value and strengthened the $P$-value compared to these variables alone (Table 4). By entering these variables into a multivariate analysis model, the increase in the hazard ratio for pCA IX and MMP-9 when coexpressed with EGFR was shown to be significant (Tables 5 and 6). However, this was not the case for coexpression of mCA IX.

\section{Survival analysis for EGFR coexpression, no coexpression and no EGFR expression}

In view of the associations between pCA IX, MMP 9 and EGFR expression, the study population was divided into three groups: group 1 expression of EGFR in the absence of pCA IX and MMP-9; group 2 no expression of EGFR; and group 3 coexpression of EGFR with either pCA IX or MMP-9 or both. Using the log-rank test, group 3 had a worse prognosis than either groups 1 or 2 $(P=0.0003$ and 0.027 , respectively) and group 1 had a better

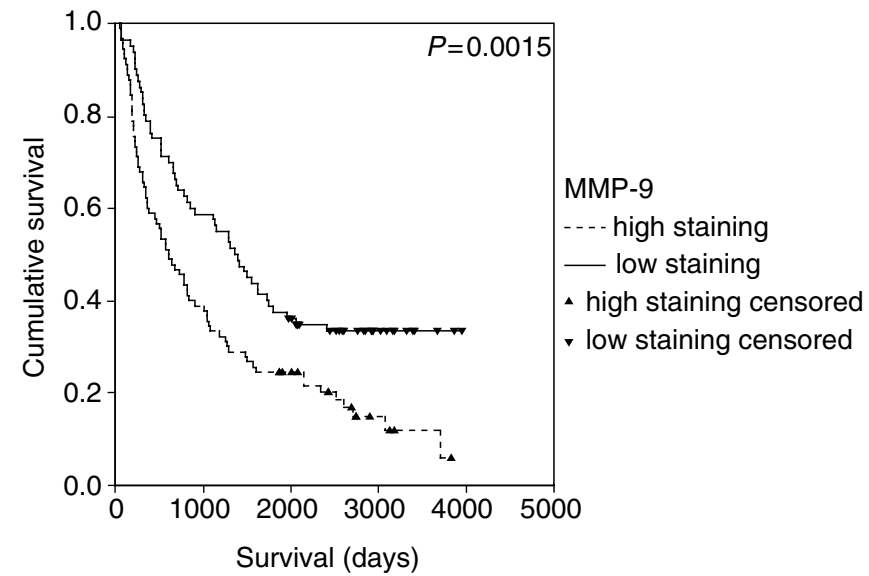

Figure I Kaplan-Meier survival curve and log-rank P-value for MMP-9 expression in NSCLC.

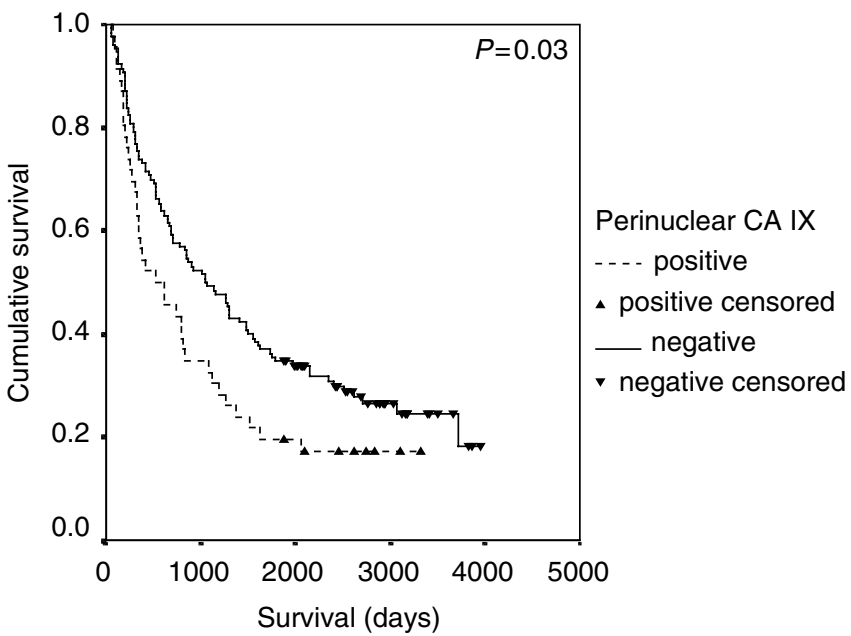

Figure 2 Kaplan-Meier survival curve and log-rank $P$-value for pCA IX expression in NSCLC.

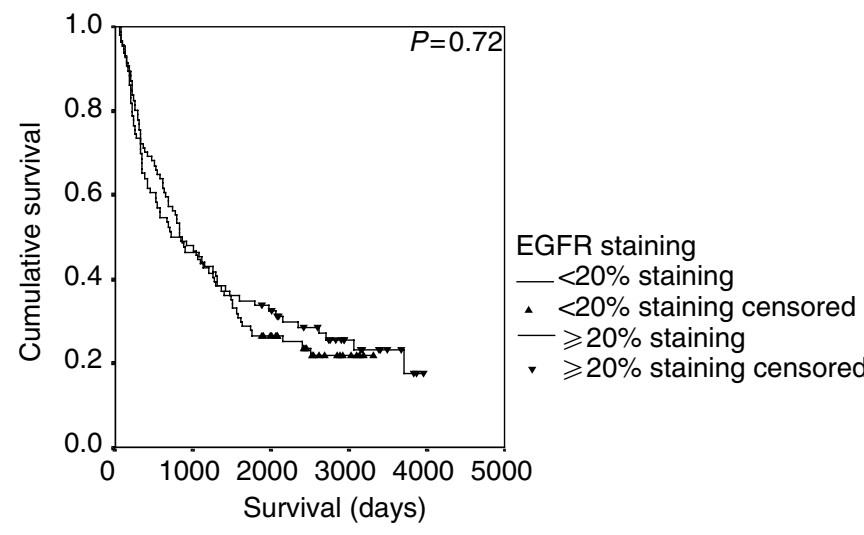

Figure 3 Kaplan-Meier survival curve and log-rank P-value for EGFR expression in NSCLC.

Table 4 Univariate survival of EGFR-related biological variables using Cox's regression analysis

\begin{tabular}{|c|c|c|c|c|}
\hline Prognostic factor & $\mathbf{N}$ & Hazard ratio & $95 \% \mathrm{Cl}$ & $P$-value \\
\hline \multicolumn{5}{|l|}{ EGFR } \\
\hline$<20 \%$ & 86 & 1 & & \multirow[t]{2}{*}{0.64} \\
\hline$\geqslant 20 \%$ & 93 & $\begin{array}{l}1.08 \\
179\end{array}$ & $0.77-|.5|$ & \\
\hline \multicolumn{5}{|l|}{ MMP-9 } \\
\hline$<20 \%$ & 80 & 1 & & \multirow[t]{2}{*}{0.001} \\
\hline$\geqslant 20 \%$ & 89 & $\begin{array}{l}1.79 \\
169\end{array}$ & $1.26-2.55$ & \\
\hline \multicolumn{5}{|c|}{ EGFR/MMP-9 coexpression } \\
\hline$-v e$ & 61 & 1.00 & & \multirow{2}{*}{$<0.000$} \\
\hline +ve & 107 & $\begin{array}{l}2.19 \\
168\end{array}$ & $1.54-3.1408$ & \\
\hline \multicolumn{5}{|l|}{$p C A I X$} \\
\hline Positive & 46 & 1.0 & & \multirow[t]{3}{*}{0.044} \\
\hline Negative & 131 & 1.50 & $1.03-2.19$ & \\
\hline & 177 & & & \\
\hline \multicolumn{5}{|c|}{ EGFR/pCA IX coexpression } \\
\hline -ve & 142 & 1 & & \multirow[t]{3}{*}{0.003} \\
\hline +ve & 34 & 1.86 & $1.24-2.80$ & \\
\hline & 176 & & & \\
\hline
\end{tabular}

EGFR = epidermal growth factor receptor; $M M P-9=$ metalloproteinase-9; $\mathrm{pCA}=$ perinuclear carbonic anhydrase; $95 \% \mathrm{Cl}=95 \%$ confidence intervals.

Table 5 Cox's regression model for EGFR/MMP-9 coexpression

\begin{tabular}{|c|c|c|c|}
\hline Variable & Harzard ratio & $95 \% \mathrm{Cl}$ & $P$-value \\
\hline \multicolumn{4}{|l|}{ MMP-9 } \\
\hline$<20 \%$ & 1.0 & & 0.792 \\
\hline$\geqslant 20 \%$ & 0.93 & $0.54-1.59$ & \\
\hline \multicolumn{4}{|l|}{ EGFR } \\
\hline$<20 \%$ & 1.0 & & 0.015 \\
\hline$\geqslant 20 \%$ & 0.52 & $0.31-0.88$ & \\
\hline \multicolumn{4}{|c|}{ MMP-9/EGFR coexpression } \\
\hline Negative & 1.0 & & $<0.001$ \\
\hline Positive & 3.55 & $1.73-7.26$ & \\
\hline
\end{tabular}

EGFR $=$ epidermal growth factor receptor; MMP-9=metalloproteinase-9; 95\% $\mathrm{Cl}=95 \%$ confidence intervals.

prognosis than group $2(P=0.036)$ (Figure 4) (Cox's regression analysis, Table 7$)$. Using the $\chi^{2}$ test, the pattern of EGFR expression (membranous, cytoplasmic or mixed) did not differ between the groups. 


\section{Multivariate analysis}

The clinicopathological factors, stage, gender, positive margins and the use of adjuvant radiotherapy, were entered into a multivariate model with the three groups. Stage, gender and Epidermal growth factor receptor groupings were independent prognostic variables (Table 8).

\section{DISCUSSION}

EGFR expression was closely associated with CA IX expression in agreement with the study by Giatromanolaki et al We have previously reported two important patterns of CA IX staining in

Table 6 Cox's regression model for EGFR/pCA IX coexpression

\begin{tabular}{lccc}
\hline Variable & Hazard ratio & $\mathbf{9 5 \%} \mathbf{~ C l}$ & P-value \\
\hline $\begin{array}{l}\text { PCA IX } \\
\quad \text { Negative }\end{array}$ & 1.0 & & \\
$\quad$ Positive & 0.90 & $0.42-1.89$ & 0.781 \\
EGFR & & & \\
$\quad<20 \%$ & 1.0 & & \\
$\geqslant 20 \%$ & 0.75 & $0.50-1.13$ & 0.172 \\
PCA IXIEGFR coexpression \\
$\begin{array}{l}\text { Negative } \\
\text { Positive }\end{array}$ & 1.0 & & \\
\hline
\end{tabular}

EGFR = epidermal growth factor receptor, pCA = perinuclear carbonic anhydrase; $95 \% \mathrm{Cl}=95 \%$ confidence intervals.
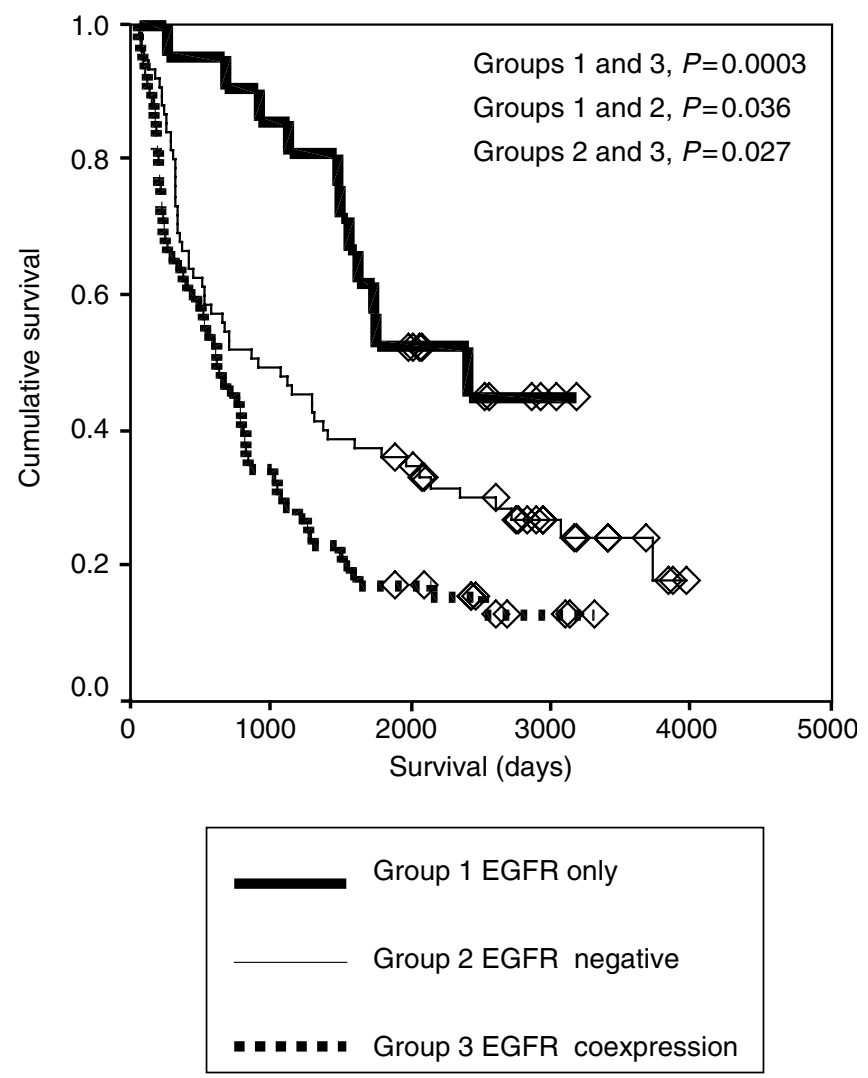

Figure 4 Survival curves for EGFR expression alone (group I), EGFR negative (group 2) and coexpression of EGFR with either MMP-9 or CA IX or both (group 3).
Table 7 Cox's regression analysis for pCA IX, MMP-9 and EGFR coexpression

\begin{tabular}{|c|c|c|}
\hline Hazard ratio & $95 \% \mathrm{Cl}$ & $P$-value \\
\hline \multicolumn{3}{|c|}{ No EGFR expression $(N=21)$} \\
\hline 1.0 & & 0.0002 \\
\hline \multicolumn{3}{|c|}{ EGFR only $(N=75)$} \\
\hline 0.49 & $0.93-0.26$ & 0.031 \\
\hline \multicolumn{3}{|c|}{ EGFR/MMP-9 or pCA IX coexpression $(N=70)$} \\
\hline 3.25 & $1.70-6.20$ & 0.0004 \\
\hline
\end{tabular}

Table 8 Multivariate analysis of clinicopathological variables and EGFR groupings

\begin{tabular}{llcll}
\hline Number & Variable & Hazard ratio & $\mathbf{9 5 \%} \mathbf{C l}$ & P-value \\
\hline 82 & Stage 1 & 1.0 & & 0.001 \\
46 & Stage 2 & 1.55 & $1.02-2.37$ & 0.04 \\
38 & Stage 3A & 2.26 & $1.47-3.49$ & 0.0002 \\
& & & & \\
51 & Female & 1.0 & & \\
115 & Male & 1.76 & $1.17-2.66$ & 0.007 \\
& & & & \\
71 & EGFR only & 1.0 & & 0.0003 \\
70 & No EGFR & 2.11 & $1.1-4.08$ & 0.025 \\
\hline
\end{tabular}

EGFR $=$ epidermal growth factor receptor; $95 \% \mathrm{Cl}=95 \%$ confidence intervals

NSCLC, mCA IX, which has been proposed to be a marker of tumour cell hypoxia and pCA IX that is associated with a poor prognosis (Swinson et al, 2003). pCA IX was closely related to the mCA IX group as all pCA IX tumour cells expressed mCA IX and the majority of pCA IX positive cases ( 42 of 46 ) had high mCA IX expression. The association between EGFR and pCA IX was stronger than between mCA IX and EGFR. The latter relationship appeared to be dependent on the former as when the pCA IX subgroup was subtracted from the series the relationship between mCA IX and EGFR was lost. When EGFR was coexpressed with pCA IX, a worse prognosis was observed than when either of these factors were expressed on their own, hence mirroring the relationship between MMP-9 and EGFR (Cox et al, 2000). As such, a model was developed where the series was split into three groups. The first group expressed EGFR alone; the second did not express EGFR and the third expressed EGFR with either MMP-9 or pCA IX or both. The prognosis of the third group was the worst, whereas the prognosis of the first was the best.

The polarisation of prognosis depending on whether or not EGFR is coexpressed with related factors provides grounds for the hypothesis that coexpression of EGFR with either MMP-9 or pCA IX or both represents patients with activated EGFR. This hypothesis explains the differences in prognosis between group 3 and the other two groups. This hypothesis is also supported by a small study that has reported that phosphorylated EGFR is associated with a poor prognosis in NSCLC (Kanematsu et al, 2003).

The difference between groups 1 and 2 is less easily explained. One explanation could be that some patients in group 2 expressed pCA IX and MMP-9, both markers of a poor prognosis, whereas by definition no patients in group 1 expressed these factors. However, subtraction of patients with either MMP-9 or pCA IX or both expression from group 2 did not alter the survival difference between the two groups (data not shown). 
Alternatively in the downstream marker negative patients, EGFR may stimulate proapoptotic pathways. Recent work has shown that tumour cell lines expressing high levels of EGFR may undergo apoptosis, particularly following exposure to EGF. Increasing the level of EGFR expression in a variety of cell types predictably leads to apoptosis, a process that requires an active tyrosine kinase but not EGFR autophosphorylation sites (Gulli et al, 1996; Hognason et al, 2001). Further clinical evidence for a beneficial effect has been observed in patients receiving cisplatin chemotherapy for advanced NSCLC, where EGFR expression has been associated with a better prognosis (Bailey et al, 2004).

In summary, we have demonstrated an association between EGFR and different patterns of CA IX expression and have previously demonstrated a similar relationship between EGFR and MMP-9. We have hypothesised that cases with coexpression of

\section{REFERENCES}

Abdollahi A, Bao R, Hamilton TC (1999) Lot1 is a growth suppressor gene down-regulated by the epidermal growth factor receptor ligands and encodes a nuclear zinc-finger protein. Oncogene 18: 6477-6487

Bailey LR, Janas M, Schmidt K, Bindsley N, Wolf M, Grous J, Askaa J, Herbst R, Johnson D, Giaccone G (2004) Evaluation of epidermal growth factor receptor (egfr) as a predictive marker in patients with non-small cell lung cancer (nsclc) receiving first-line gentifinib combined with cisplatin based chemotherapy. Proc Am Soc Clin Oncol 23: 618

Clarke K, Smith K, Gullick WJ, Harris AL (2001) Mutant epidermal growth factor receptor enhances induction of vascular endothelial growth factor by hypoxia and insulin-like growth factor-1 via a pi3 kinase dependent pathway. Br J Cancer 84: 1322 - 1329

Cohen S, Carpenter G, King Jr L (1981) Epidermal growth factor-receptorprotein kinase interactions. Prog Clin Biol Res 66: 557-567

Cohen S, Carpenter G, King LJ (1980) Epidermal growth factor receptor-kinase interactions: co-purification of receptor and epidermal growth factor-enhanced phosphorylation activity. J Biol Chem 255: $4834-4842$

Cornianu M, Tudose N (1997) Immunohistochemical markers in the morphological diagnosis of lung carcinoma. Rom J Morphol Embryol 43: $181-191$

Cox G, Jones JL, O'Byrne KJ (2000) Matrix metalloproteinase 9 and the epidermal growth factor signal pathway in operable non-small cell lung cancer. Clin Cancer Res 6: 2349-2355

D'Amico TA, Massey M, Herndon II JE, Moore MB, Harpole Jr DH (1999) A biologic risk model for stage i lung cancer: immunohistochemical analysis of 408 patients with the use of ten molecular markers. J Thorac Cardiovasc Surg 117: 736-743

Di Gennaro E, Barbarino M, Bruzzese F, De Lorenzo S, Caraglia M, Abbruzzese A, Avallone A, Comella P, Caponigro F, Pepe S, Budillon A (2003) Critical role of both p27kip1and p21cip1/waf1 in the antiproliferative effect of zd1839 ('iressa'), an epidermal growth factor receptor tyrosine kinase inhibitor, in head and neck squamous carcinoma cells. $J$ Cell Physiol 195: 139-150

Fontanini G, De Laurentiis M, Vignati S, Chine S, Lucchi M, Silvestri V, Mussi A, De Placido S, Tortora G, Bianco AR, Gullick W, Angeletti CA, Bevilacqua G, Ciardiello F (1998) Evaluation of epidermal growth factorrelated growth factors and receptors and of neoangiogenesis in completely resected stage i-iiia non-small-cell lung cancer: amphiregulin and microvessel count are independent prognostic indicators of survival. Clin Cancer Res 4: 241-249

Fu XL, Zhu XZ, Shi DR, Xiu LZ, Wang LJ, Zhao S, Qian H, Lu HF, Xiang YB, Jiang GL (1999) Study of prognostic predictors for non-small cell lung cancer. Lung Cancer 23: $143-152$

Giaccone G, Herbst RS, Manegold C, Scagliotti G, Rosell R, Miller V, Natale RB, Schiller JH, Von Pawel J, Pluzanska A, Gatzemeier U, Grous J, Ochs JS, Averbuch SD, Wolf MK, Rennie P, Fandi A, Johnson DH (2004) Gefitinib in combination with gemcitabine and cisplatin in advanced non-small-cell lung cancer: a phase iii trial - intact 1. J Clin Oncol 22: $777-784$

Giatromanolaki A, Koukourakis MI, Sivridis E, Pastorek J, Wykoff CC, Gatter KC, Harris AL (2001) Expression of hypoxia-inducible carbonic
EGFR with either MMP-9 or pCA IX or both represent cases with activated EGFR. Hence, promoting an aggressive NSCLC phenotype. By developing an assay to select cases with activated EGFR, a cohort of patients may be identified that are highly responsive to anti-EGFR therapy. Such studies are under way using specimens collected from the large number of clinical trials exploring EGFR-targeted therapies in NSCLC (Lynch et al, 2004a; Paez et al, 2004). The implications of such a finding may have great clinical benefits.

\section{ACKNOWLEDGEMENTS}

We thank the Institute of Cancer Studies and the Institute for Lung Health at Leicester University. This work was funded by a Medisearch grant, University of Leicester, UK. anhydrase-9 relates to angiogenic pathways and independently to poor outcome in non-small cell lung cancer. Cancer Res 61: 7992-7998

Gildea JJ, Harding MA, Seraj MJ, Gulding KM, Theodorescu D (2002) The role of ral a in epidermal growth factor receptor-regulated cell motility. Cancer Res 62: $982-985$

Greatens TM, Niehans GA, Rubins JB, Jessurun J, Kratzke RA, Maddaus MA, Niewoehner DE (1998) Do molecular markers predict survival in non-small-cell lung cancer? Am J Respir Crit Care Med 157: $1093-1097$

Gulli LF, Palmer KC, Chen YQ, Reddy KB (1996) Epidermal growth factorinduced apoptosis in a431 cells can be reversed by reducing the tyrosine kinase activity. Cell Growth Differ 7: 173-178

Herbst RS, Giaccone G, Schiller JH, Natale RB, Miller V, Manegold C, Scagliotti G, Rosell R, Oliff I, Reeves JA, Wolf MK, Krebs AD, Averbuch SD, Ochs JS, Grous J, Fandi A, Johnson DH (2004a) Gefitinib in combination with paclitaxel and carboplatin in advanced non-small-cell lung cancer: a phase iii trial - intact 2. J Clin Oncol 22: 785-794

Herbst RS, Prager D, Hermann R, Miller V, Fehrenbacher L, Hoffman P, Johnson B, Sandler AB, Mass R, Johnson DH (2004b) Tribute - a phase ii trial of erlotinib hcl (osi-774) combined with carboplatin and paclitaxel (cp) chemotherapy in advanced non-small cell lung cancer (nsclc). Proc Am Soc Clin Oncol 23: 617

Hirata A, Ogawa S, Kometani T, Kuwano T, Naito S, Kuwano M, Ono M (2002) Zd1839 (iressa) induces antiangiogenic effects through inhibition of epidermal growth factor receptor tyrosine kinase. Cancer Res 62: $2554-2560$

Hirsch FR, Varella-Garcia M, Bunn Jr PA, Di Maria MV, Veve R, Bremmes RM, Baron AE, Zeng C, Franklin WA (2003) Epidermal growth factor receptor in non-small-cell lung carcinomas: correlation between gene copy number and protein expression and impact on prognosis. J Clin Oncol 21: $3798-3807$

Hognason T, Chatterjee S, Vartanian T, Ratan RR, Ernewein KM, Habib AA (2001) Epidermal growth factor receptor induced apoptosis: potentiation by inhibition of ras signaling. FEBS Lett 491: 9-15

Kanematsu T, Yano S, Uehara H, Bando Y, Sone S (2003) Phosphorylation, but not overexpression, of epidermal growth factor receptor is associated with poor prognosis of non-small cell lung cancer patients. Oncol Res 13: $289-298$

Lynch TJ, Bell DW, Sordella R, Gurubhagavatula S, Okimoto RA, Brannigan BW, Harris PL, Haserlat SM, Supko JG, Haluska FG, Louis DN, Christiani DC, Settleman J, Haber DA (2004a) Activating mutations in the epidermal growth factor receptor underlying responsiveness of nonsmall-cell lung cancer to gefitinib. $N$ Engl J Med 350: 2129-2139, (Epub 2004 Apr 2129)

Lynch TJ, Lilenbaum R, Bonomi P, Ansari R, Govindan R, Janne PA, Hanna N (2004b) A phase ii trial of cetuximab as therapy for recurrent nonsmall cell lung cancer (nsclc). Proc Am Soc Clin Oncol 23: 634

Mukohara T, Kudoh S, Yamauchi S, Kimura T, Yoshimura N, Kanazawa H, Hirata K, Wanibuchi H, Fukushima S, Inoue K, Yoshikawa J (2003) Expression of epidermal growth factor receptor (egfr) and downstreamactivated peptides in surgically excised non-small-cell lung cancer (nsclc). Lung Cancer 41: 123-130 
O’Byrne KJ, Cox G, Swinson D, Richardson D, Edwards JG, Lolljee J, Andi A, Koukourakis MI, Giatromanolaki A, Gatter K, Harris AL, Waller D, Jones JL (2001) Towards a biological staging model for operable nonsmall cell lung cancer. Lung Cancer 34(Suppl 2): S83-S89

Ohsaki Y, Tanno S, Fujita Y, Toyoshima E, Fujiuchi S, Nishigaki Y, Ishida S, Nagase A, Miyokawa N, Hirata S, Kikuchi K (2000) Epidermal growth factor receptor expression correlates with poor prognosis in non-small cell lung cancer patients with p53 overexpression. Oncol Rep 7: 603-607

Onn A, Correa AM, Gilcrease M, Moran C, Roach JS, Isobe T, Bucana CD, Hong WK, Putnam JB, Herbst RS (2003) Epidermal growth factor receptor, her2, and c-kit as predictors of outcome in stage i non-small cell lung cancer. Proc Am Soc Clin 22: 635

Paez JG, Janne PA, Lee JC, Tracy S, Greulich H, Gabriel S, Herman P, Kaye FJ, Lindeman N, Boggon TJ, Naoki K, Sasaki H, Fujii Y, Eck MJ, Sellers WR, Johnson BE, Meyerson M (2004) Egfr mutations in lung cancer: correlation with clinical response to gefitinib therapy. Science 304: 1497 1500, Epub 2004 Apr 1429

Pastorino U, Andreola S, Tagliabue E, Pezzella F, Incarbone M, Sozzi G, Buyse M, Menard S, Pierotti M, Rilke F (1997) Immunocytochemical markers in stage i lung cancer: relevance to prognosis. J Clin Oncol 15: $2858-2865$

Perrotte P, Matsumoto T, Inoue K, Kuniyasu H, Eve BY, Hicklin DJ, Radinsky R, Dinney CP (1999) Anti-epidermal growth factor receptor antibody c225 inhibits angiogenesis in human transitional cell carcinoma growing orthotopically in nude mice. Clin Cancer Res 5: 257-265

Pfeiffer P, Clausen PP, Andersen K, Rose C (1996) Lack of prognostic significance of epidermal growth factor receptor and the oncoprotein p185her-2 in patients with systemically untreated non-small-cell lung cancer: an immunohistochemical study on cryosections. Br J Cancer 74: $86-91$

Rosen K, Coll ML, Li A, Filmus J (2001) Transforming growth factor-alpha prevents detachment-induced inhibition of c-src kinase activity, bcl-xl down-regulation, and apoptosis of intestinal epithelial cells. J Biol Chem 276: $37273-37279$

Rusch V, Klimstra D, Venkatraman E, Pisters PW, Langenfeld J, Dmitrovsky E (1997) Overexpression of the epidermal growth factor receptor and its ligand transforming growth factor alpha is frequent in resectable non-small cell lung cancer but does not predict tumor progression. Clin Cancer Res 3: 515-522

Selvaggi G, Scagliotti GV, Novello S, Leonardo E, Lausi P, Borasio P, Torri W (2002) Prospective evaluation of epidermal growth factor (egfr) expression in completely resected non-small cell lung cancer (nsclc): effects of egfr on long-term follow up. Proc Am Soc Clin 21, (Abstr 1345)

Semenza G (2002) Signal transduction to hypoxia-inducible factor 1 . Biochem Pharmacol 64: 993 - 998

Swinson DE, Jones JL, Cox G, Richardson D, Harris AL, O’Byrne KJ (2004) Hypoxia-inducible factor-1alpha in non small cell lung cancer: relation to growth factor, protease and apoptosis pathways. Int J Cancer 111: $43-50$

Swinson DE, Jones JL, Richardson D, Wykoff C, Turley H, Pastorek J, Taub N, Harris AL, O’Byrne KJ (2003) Carbonic anhydrase ix expression, a novel surrogate marker of tumor hypoxia, is associated with a poor prognosis in non-small-cell lung cancer. J Clin Oncol 21: 473-482

Tzahar E, Waterman H, Chen X, Levkowitz G, Karunagaran D, Lavi S, Ratzkin BJ, Yarden Y (1996) A hierarchical network of interreceptor interactions determines signal transduction by neu differentiation factor/ neuregulin and epidermal growth factor. Mol Cell Biol 16: 5276-5287

Veale D, Ashcroft T, Marsh C, Gibson GJ, Harris AL (1987) Epidermal growth factor receptors in non-small cell lung cancer. $\mathrm{Br} J$ Cancer 55: $513-516$

Volm M, Drings P, Wodrich W (1993) Prognostic significance of the expression of c-fos, c-jun and c-erbb-1 oncogene products in human squamous cell lung carcinomas. J Cancer Res Clin Oncol 119: 507-510

Westermark B, Magnusson A, Heldin CH (1982) Effect of epidermal growth factor on membrane motility and cell locomotion in cultures of human clonal glioma cells. J Neurosci Res 8: 491-507

Wykoff CC, Beasley NJ, Watson PH, Turner KJ, Pastorek J, Sibtain A, Wilson GD, Turley H, Talks KL, Maxwell PH, Pugh CW, Ratcliffe PJ, Harris AL (2000) Hypoxia-inducible expression of tumor-associated carbonic anhydrases. Cancer Res 60: 7075-7083

Yarden Y, Ullrich A (1988) Growth factor receptor tyrosine kinases. Annu Rev Biochem 57: $443-478$ 